\title{
Kinetics of dimethyl sulfide (DMS) reactions with isoprene-derived Criegee intermediates studied with direct UV absorption
}

\author{
Mei-Tsan Kuo ${ }^{1}$, Isabelle Weber ${ }^{2,6}$, Christa Fittschen ${ }^{2}$, Luc Vereecken ${ }^{3,4}$, and Jim Jr-Min Lin ${ }^{1,5}$ \\ ${ }^{1}$ Institute of Atomic and Molecular Sciences, Academia Sinica, Taipei 10617, Taiwan \\ ${ }^{2}$ Univ. Lille, CNRS, UMR 8522 - PC2A - Physicochimie des Processus de Combustion et de l'Atmosphère, \\ 59000 Lille, France \\ ${ }^{3}$ Atmospheric Chemistry Department, Max Planck Institute for Chemistry, Hahn-Meitner-Weg 1, 55128 Mainz, Germany \\ ${ }^{4}$ Institute for Energy and Climate Research, IEK-8: Troposphere, Forschungszentrum Jülich GmbH, 52428 Jülich, Germany \\ ${ }^{5}$ Department of Chemistry, National Taiwan University, Taipei 10617, Taiwan \\ ${ }^{6}$ Present address: Department of Applied Chemistry and Institute of Molecular Science, National Chiao Tung University, \\ Hsinchu 30010, Taiwan
}

Correspondence: Jim Jr-Min Lin (jimlin@ gate.sinica.edu.tw)

Received: 18 May 2020 - Discussion started: 10 June 2020

Revised: 9 September 2020 - Accepted: 23 September 2020 - Published: 6 November 2020

\begin{abstract}
Criegee intermediates (CIs) are formed in the ozonolysis of unsaturated hydrocarbons and play a role in atmospheric chemistry as a non-photolytic $\mathrm{OH}$ source or a strong oxidant. Using a relative rate method in an ozonolysis experiment, Newland et al. (2015) reported high reactivity of isoprene-derived Criegee intermediates towards dimethyl sulfide (DMS) relative to that towards $\mathrm{SO}_{2}$ with the ratio of the rate coefficients $k_{\mathrm{DMS}+\mathrm{CI}} / k_{\mathrm{SO}_{2}+\mathrm{CI}}=3.5 \pm 1.8$. Here we reinvestigated the kinetics of DMS reactions with two major Criegee intermediates formed in isoprene ozonolysis, $\mathrm{CH}_{2} \mathrm{OO}$, and methyl vinyl ketone oxide (MVKO). The individual CI was prepared following the reported photolytic method with suitable (diiodo) precursors in the presence of $\mathrm{O}_{2}$. The concentration of $\mathrm{CH}_{2} \mathrm{OO}$ or $\mathrm{MVKO}$ was monitored directly in real time through their intense UV-visible absorption. Our results indicate the reactions of DMS with $\mathrm{CH}_{2} \mathrm{OO}$ and $\mathrm{MVKO}$ are both very slow; the upper limits of the rate coefficients are 4 orders of magnitude smaller than the rate coefficient reported by Newland et al. (2015) These results suggest that the ozonolysis experiment could be complicated such that interpretation should be careful and these CIs would not oxidize atmospheric DMS at any substantial level.
\end{abstract}

\section{Introduction}

As a non-photolytic $\mathrm{OH}$ source or a strong oxidant, Criegee intermediates (CIs) influence the chemical processes in the troposphere (Nguyen et al., 2016; Novelli et al., 2014; Johnson and Marston, 2008; Atkinson and Aschmann, 1993; Gutbrod et al., 1997; Zhang et al., 2002) and, ultimately, have an impact on the formation of secondary aerosols and other pollutants (Percival et al., 2013; Wang et al., 2016; Meidan et al., 2019). A detailed understanding of CI chemistry under atmospheric conditions is, thus, necessary to be able to accurately predict and describe the evolution of Earth's atmosphere.

However, due to their high reactivity and, hence, short lifetimes, laboratory studies of the reactions of CIs have been challenging until the work by Welz et al., who reported a novel method to efficiently generate CIs other than through ozonolysis of alkenes (Welz et al., 2012). They utilized Reactions (R1) and (R2) to prepare $\mathrm{CH}_{2} \mathrm{OO}$ and directly measured the rate coefficients of $\mathrm{CH}_{2} \mathrm{OO}$ reactions with $\mathrm{SO}_{2}$ and $\mathrm{NO}_{2}$ by following the time-resolved decay of $\mathrm{CH}_{2} \mathrm{OO}$.

$$
\begin{aligned}
& \mathrm{CH}_{2} \mathrm{I}_{2}+h v \rightarrow \mathrm{CH}_{2} \mathrm{I}+\mathrm{I} \\
& \mathrm{CH}_{2} \mathrm{I}+\mathrm{O}_{2} \rightarrow \mathrm{CH}_{2} \mathrm{OO}+\mathrm{I}
\end{aligned}
$$

Surprisingly, the obtained rate coefficients are up to $10^{4}$ times larger than previous results deduced from ozonolysis experiments (Johnson et al., 2001; Hatakeyama and Aki- 
moto, 1994; Johnson and Marston, 2008). For ozonolysis experiments, typically only the ratios of certain reaction rate coefficients are obtained. The researchers have to compare with (at least) one absolute rate coefficient to get the rest rate coefficients. Unfortunately, the selected absolute rate coefficient (at that time) has large uncertainty, which propagates to other reported values. In addition, the reaction mechanism may be rather complicated and even the ratios of the rate coefficients need to be treated with care.

After this pioneering work, the same method has been applied for generation of other CIs, like $\mathrm{CH}_{3} \mathrm{CHOO}$ (Taatjes et al., 2013), $\left(\mathrm{CH}_{3}\right)_{2} \mathrm{COO}$ (Liu et al., 2014a; Chang et al., 2016), methyl vinyl ketone oxide (MVKO) (Barber et al., 2018), methacrolein oxide (MACRO) (Vansco et al., 2019), etc. These CIs have been identified with various detection methods, like photoionization mass spectrometry (Taatjes et al., 2013), infrared action (Liu et al., 2014b) and absorption (Su et al., 2013; Lin et al., 2015) spectroscopy, UV-visible absorption or depletion spectroscopy (Liu et al., 2014a; Beames et al., 2013; Sheps, 2013; Smith et al., 2014; Chang et al., 2016; Ting et al., 2014), microwave spectroscopy (McCarthy et al., 2013; Nakajima et al., 2015), etc. In addition, utilizing the direct detection of CIs, a number of kinetic investigations of $\mathrm{CI}$ reactions, e.g. with $\mathrm{SO}_{2}$ (Huang et al., 2015), water vapor (Chao et al., 2015), alcohols (Chao et al., 2019), thiols (Li et al., 2019), amines (Chhantyal-Pun et al., 2019), carbonyl molecules (Taatjes et al., 2012), and organic (Welz et al., 2014) and inorganic (Foreman et al., 2016) acids, etc., have been reported (Lee, 2015; Osborn and Taatjes, 2015; Lin and Chao, 2017; Khan et al., 2018; Cox et al., 2020).

Recently, Newland et al. (2015) studied the reactivity of CIs with $\mathrm{H}_{2} \mathrm{O}$ and, for the first time, with dimethyl sulfide (DMS) in the ozonolysis of isoprene at the EUPHORE simulation chamber facility and found a rapid reaction of CIs with DMS. A mixture of $\mathrm{CH}_{2} \mathrm{OO}$, MVKO, and MACRO was generated through ozonolysis of isoprene with a total CI yield of $0.56 \pm 0.03$ (Newland et al., 2015). The relative yields of the individual CIs have previously been estimated to be 0.58 or 0.55 for $\mathrm{CH}_{2} \mathrm{OO}, 0.23$ or 0.37 for MVKO, and 0.19 or 0.08 for MACRO by an analysis based on a large laboratory, modeling, and field data set (Nguyen et al., 2016) or an earlier theoretical calculation (Zhang et al., 2002), respectively. To determine reaction rates, Newland et al. (2015) used a relative rate method and followed the removal of $\mathrm{SO}_{2}$ versus the removal of other reactants. For the reaction CI + DMS relative to the reaction $\mathrm{CI}+\mathrm{SO}_{2}$, they obtained a relative rate coefficient of $k_{\mathrm{DMS}+\mathrm{CI}} / k_{\mathrm{SO}_{2}+\mathrm{CI}}=3.5 \pm 1.8$ (Newland et al., 2015). Since the reactions of typical CIs with $\mathrm{SO}_{2}$ are very fast, with rate coefficients on the order of $4 \times 10^{-11} \mathrm{~cm}^{3} \mathrm{~s}^{-1}$ (Welz et al., 2012; Lee, 2015; Osborn and Taatjes, 2015; Lin and Chao, 2017; Khan et al., 2018), this result suggests that the reaction of CI + DMS is extremely fast, with a rate coefficient of ca. $10^{-10} \mathrm{~cm}^{3} \mathrm{~s}^{-1}$. This value is extremely large, close to those of the fastest reactions of CIs.
Newland et al. (2015), who used ozonolysis of isoprene to generate a mixture of CIs ( $\mathrm{CH}_{2} \mathrm{OO}$, MVKO, and MACRO), reported a combined reactivity of these CIs toward DMS and $\mathrm{H}_{2} \mathrm{O}$ under conditions similar to the atmospheric boundary layer. Their reported rate coefficients may not correspond to those of single elementary reactions.

DMS is the major sulfur-containing species in the atmosphere with high abundances in the marine boundary layer (Yvon et al., 1996) but also, for example, in the Amazon basin (Jardine et al., 2015) and has been shown to play an important role in the formation of $\mathrm{SO}_{2}$ and sulfuric acid, which are precursors of sulfide aerosols (Andreae and Crutzen, 1997; Charlson et al., 1987; Faloona, 2009). The results of Newland et al. (2015) therefore suggest that in regions with high concentrations of CIs, the $\mathrm{CI}+$ DMS reactions will have a comparable impact on the oxidation of DMS, considering the main atmospheric oxidants are $\mathrm{OH}$ and $\mathrm{NO}_{3}\left(k_{\mathrm{DMS}+\mathrm{OH}}=4.8 \times 10^{-12} \mathrm{~cm}^{3} \mathrm{~s}^{-1}\right.$, $k_{\mathrm{DMS}+\mathrm{NO}_{3}}=1.1 \times 10^{-12} \mathrm{~cm}^{3} \mathrm{~s}^{-1}$; Atkinson et al., 2004).

Here we report the first direct kinetic study of DMS reactions with $\mathrm{CH}_{2} \mathrm{OO}$ and $\mathrm{MVKO}$, the main CIs formed in the ozonolysis of isoprene. CIs have strong UV-visible absorption (Lin and Chao, 2017). For example, $\mathrm{CH}_{2} \mathrm{OO}$ and MVKO absorb strongly (peak cross section $\sigma \geq 1 \times 10^{-17} \mathrm{~cm}^{2}$ ) in the wavelength ranges of $285-400 \mathrm{~nm}$ (Ting et al., 2014; Lewis et al., 2015) and 315-425 nm (Vansco et al., 2018) ( $>20 \%$ of the peak value), respectively. This strong and distinctive absorption has been utilized to probe CIs in a number of kinetic experiments, including their reactions with $\mathrm{SO}_{2}$, water vapor, alcohols, thiols, organic and inorganic acids, carbonyl compounds, alkenes, etc. (Khan et al., 2018; Lin and Chao, 2017; Osborn and Taatjes, 2015; Lee, 2015). In this work, both $\mathrm{CH}_{2} \mathrm{OO}$ and MVKO were directly probed in real time via their strong UV absorption at $340 \mathrm{~nm}$. For MVKO, there are four possible conformers. Following the nomenclature of Barber et al. (2018), syn- or anti-MVKO ( $E$ or Z-MVKO) has a methyl or vinyl group, respectively, at the same side of the terminal oxygen, while cis and trans refer to the orientation between the vinyl $\mathrm{C}=\mathrm{C}$ and the carbonyl $\mathrm{C}=\mathrm{O}$ bonds. It has been reported that syn- and anti-MVKO do not interconvert due to a high barrier between them, but the barrier between cis and trans forms is low enough to permit fast interconversion at $298 \mathrm{~K}$ (Barber et al., 2018; Vereecken et al., 2017). Caravan et al. (2020), have shown that anti-MVKO is unobservable under thermal $(298 \mathrm{~K})$ conditions due to short lifetime and/or low yield, and thus, the UV-vis absorption signal is from an equilibrium mixture of cis and trans forms of syn-MVKO (Caravan et al., 2020; Vereecken et al., 2017). For simplicity we will use MVKO to represent syn-MVKO ( $E$-MVKO).

Surprisingly, our experimental results do not indicate any significant reactivity of DMS with $\mathrm{CH}_{2} \mathrm{OO}$ or MVKO. We therefore propose upper limits of the rate coefficients for these reactions. Implications for atmospheric chemistry are discussed. 


\section{Method}

\subsection{Experimental setup}

The experimental setup has been described previously (Chao et al., 2019; Chao et al., 2015). To generate $\mathrm{CH}_{2} \mathrm{OO}$ and MVKO, we followed the approaches of Welz et al. (2012) and Barber et al. (2018), respectively. The MVKO formation is through the reaction sequence $\mathrm{ICH}_{2}-\mathrm{CH}=\mathrm{C}(\mathrm{I})-$ $\mathrm{CH}_{3}+h v \rightarrow \mathrm{CH}_{3}\left(\mathrm{C}_{2} \mathrm{H}_{3}\right) \mathrm{CI}+\mathrm{I}, \mathrm{CH}_{3}\left(\mathrm{C}_{2} \mathrm{H}_{3}\right) \mathrm{CI}+\mathrm{O}_{2} \rightarrow$ $\mathrm{MVKO}+\mathrm{I}$, analogue to Reactions (R1) and (R2). We applied a $308 \mathrm{~nm}$ photolysis laser (XeCl excimer laser) for generating $\mathrm{CH}_{2} \mathrm{OO}$, while a photolysis laser at $248 \mathrm{~nm}(\mathrm{KrF}$ excimer laser) was used for generating MVKO because the MVKO precursor absorbs $308 \mathrm{~nm}$ photons too weakly. However, a small amount of DMS would absorb $248 \mathrm{~nm}$ light and dissociate; the photodissociated DMS may affect the kinetics of the CIs. We therefore performed additional experiments by photolyzing $\mathrm{CH}_{2} \mathrm{I}_{2}$ at $248 \mathrm{~nm}$ to assess the impact of DMS photolysis at $248 \mathrm{~nm}$ on the decay of the CIs.

Experiments were conducted in a photolysis reactor (inner diameter: $1.9 \mathrm{~cm}$, effective length: $71 \mathrm{~cm}$ ). The photolysis laser beam was coupled into and out of the reactor by two long-pass filters (248 nm: Eksma Optics, custom-made $275 \mathrm{~nm}$ long pass; $308 \mathrm{~nm}$ : Semrock LP03-325RE-25) and monitored with an energy meter (Gentec-EO, QE25SP-HMB-D0). The probe light was from a plasma Xe lamp (Energetiq, EQ-99) (Su and Lin, 2013) and directed through the reactor collinearly with the photolysis beam. It passes through the reactor six times, resulting in an effective absorption path length of ca. $426 \mathrm{~cm}$. After passing through band-pass filters (340 nm, Edmund, no. 65129, $10 \mathrm{~nm}$ bandwidth, OD 4), the probe beam and a reference beam which did not pass through the reactor were both focused on a balanced photodiode detector (Thorlabs, PDB450A). Output signals were recorded in real time with a high-resolution oscilloscope (LeCroy, HDO4034, 4096 vertical resolution) and averaged for 120 laser shots (repetition rate $\sim 1 \mathrm{~Hz}$ ). We observed a small time-dependent variation in transmittance even when no precursor was introduced into the reactor. To compensate for this effect, which was caused by the optics and the photolysis laser pulse, we recorded background traces without adding the precursor before and after each set of experiments. The reported data are after background subtraction.

All reactant gas flows were controlled by calibrated mass-flow controllers (Brooks: 5850E and Bronkhorst: EL-FLOW prestige) and mixed before entering the reactor. Reactant concentrations were determined prior to the mixing of the reactant flows by UV absorption spectroscopy in two separate absorption cells for either DMS (absorption path length $90.4 \mathrm{~cm}$ for [DMS] $\leq 1.7 \times 10^{15} \mathrm{~cm}^{-3}$ or $20.1 \mathrm{~cm}$ for $[\mathrm{DMS}] \leq 8.1 \times 10^{15} \mathrm{~cm}^{-3}$ ) or the respective diiodo precursors (absorption path length $90.4 \mathrm{~cm}$ ) using the reported absorption cross sections (Sander et al., 2011; Limão-Vieira et al., 2002). However, because no absorption cross sections for 1,3-diiodo-2-butene have been reported, its absolute concentration cannot be determined. We, thus, can only report the absorbance (precursor $A b s$ ) of 1,3-diiodo-2-butene in the photolysis reactor (Table S3). Typical concentration ranges were $\quad\left[\mathrm{CH}_{2} \mathrm{I}_{2}\right]=(0.23-2.54) \times 10^{14} \mathrm{~cm}^{-3}, \quad\left[\mathrm{O}_{2}\right]=(3.28$ $3.30) \times 10^{17} \mathrm{~cm}^{-3}$, and $[\mathrm{DMS}]=(0-8.1) \times 10^{15} \mathrm{~cm}^{-3}$. We assume ideal gas behavior for the concentration calculation. The majority of the experiments were performed at 300 Torr $\left(\mathrm{N}_{2}\right)$ and $298 \mathrm{~K}$.

\subsection{Theoretical methodology}

The potential energy surface (PES) of the $\mathrm{CH}_{2} \mathrm{OO}+\mathrm{DMS}$ reaction was first explored at the M06-2X/cc-pVDZ level of theory (Dunning, 1989; Zhao and Truhlar, 2008), characterizing the geometries and rovibrational characteristics of the reactants, intermediates, and transition states for a wide range of potential reaction channels. The pathways found were re-optimized with a larger basis set using M06-2X/augcc-pV(T+d)Z, where the triple-zeta basis set is enhanced by tight $\mathrm{d}$ orbitals to improve the description of the sulfur atom bonds (Bell and Wilson, 2004; Dunning et al., 2001). Finally, CCSD(T)/aug-cc-pVTZ single-point energy calculations were performed to obtain more reliable energies (Dunning, 1989; Purvis and Bartlett, 1982). The $T_{1}$ diagnostics, all $\leq 0.026$ except for $\mathrm{CH}_{2} \mathrm{OO}(0.042)$, suggest that the calculations are not affected by strong multi-reference character in intermediates or transition states. The molecular characteristics thus obtained were used in canonical transition state theory (CTST) calculations to derive the temperature-dependent rate coefficient $k(T)$ (Truhlar et al., 1996). All calculations were performed using the Gaussian-09 software suite (Frisch et al., 2009). The Supplement discusses additional calculations.

\section{Results and discussion}

\section{1 $\mathrm{CH}_{2} \mathrm{OO}+\mathrm{DMS}$}

Representative time traces of $\mathrm{CH}_{2} \mathrm{OO}$ absorption recorded at $340 \pm 5 \mathrm{~nm}\left(\sigma=1.23 \times 10^{-17} \mathrm{~cm}^{2}\right.$ at $\left.340 \mathrm{~nm}\right)$ (Ting et al., 2014) under various [DMS] values are depicted in Fig. 1. Similar results but recorded with different initial concentrations of $\mathrm{CH}_{2} \mathrm{I}_{2}$ and/or different photolysis laser fluences are displayed in Figs. S12-S14. At $t=0, \mathrm{CH}_{2} \mathrm{OO}$ is generated within $10^{-5} \mathrm{~s}$ by photolysis of $\mathrm{CH}_{2} \mathrm{I}_{2}$ at $308 \mathrm{~nm}$ (nanosecond pulsed laser) (Reaction R1) and the fast reaction of $\mathrm{CH}_{2} \mathrm{I}$ with $\mathrm{O}_{2}$ (Reaction R2) $\left(k_{\mathrm{O}_{2}}=1.4 \times 10^{-12} \mathrm{~cm}^{3} \mathrm{~s}^{-1}\right.$ (Eskola et al., 2006); $\left.\left[\mathrm{O}_{2}\right]=3.3 \times 10^{17} \mathrm{~cm}^{-3}\right)$. The subsequent decay in absorption is due to the consumption of $\mathrm{CH}_{2} \mathrm{OO}$ either through reaction with DMS or through other processes, e.g. bimolecular reactions with radical byproducts like I atoms, wall loss, etc. In addition, self-reaction of $\mathrm{CH}_{2} \mathrm{OO}$ has been found to be rather fast $\left(k_{\mathrm{self}}=8 \times 10^{-11} \mathrm{~cm}^{3} \mathrm{~s}^{-1}\right)$ (Mir et al., 2020). However, the effect of the self-reaction (Smith et al., 


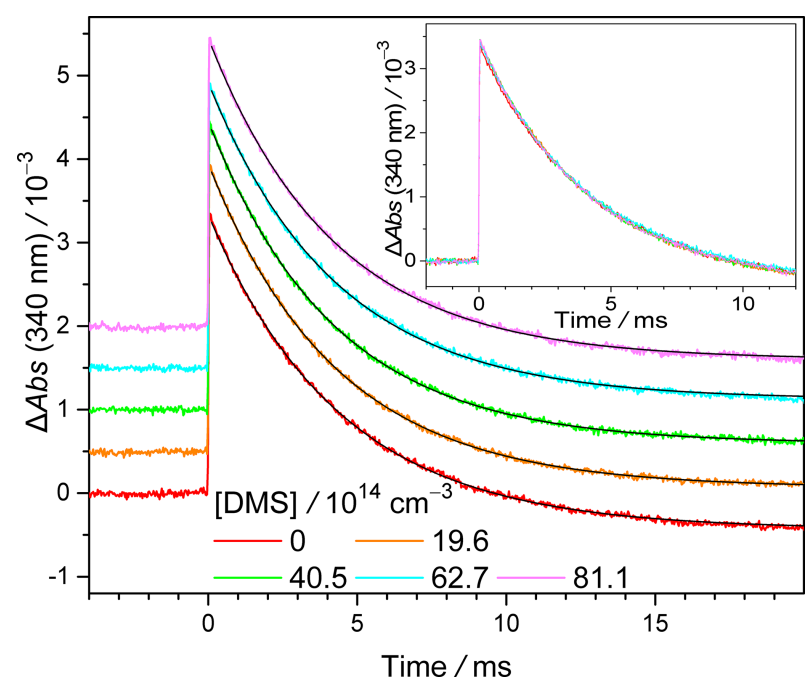

Figure 1. Representative time traces of $\mathrm{CH}_{2} \mathrm{OO}$ absorption recorded at $340 \pm 5 \mathrm{~nm}$ under various [DMS] values. The traces are shifted upward by various amounts for clearer visualization. Smooth black lines are the exponential fit. The photolysis laser ( $308 \mathrm{~nm}$ ) pulse defines $t=0$. The negative baseline (more obvious at long reaction time) is due to depletion of the precursor, $\mathrm{CH}_{2} \mathrm{I}_{2}$, which absorbs weakly at $340 \mathrm{~nm}\left(\sigma=8.33 \times 10^{-19} \mathrm{~cm}^{2}\right)$ (Atkinson et al., 2008). This depletion is constant in the probed time window and would not affect the kinetics of $\mathrm{CH}_{2} \mathrm{OO}$. The inset shows the profiles without upshifting to show the overlapping. See Exp\#1 of Table S1 for detailed experimental conditions.

2016; Li et al., 2020) would not affect the determination of $k_{\text {DMS }}$ under our experimental conditions. We can see that the decay curves of $\mathrm{CH}_{2} \mathrm{OO}$ at various [DMS] values are extremely similar to one another, indicating that the reaction of $\mathrm{CH}_{2} \mathrm{OO}+\mathrm{DMS}$ is not significant.

The decay of $\mathrm{CH}_{2} \mathrm{OO}$ can be well described with an exponential function $\left(R^{2}>0.995\right)$ (e.g. Fig. 1).

$\left[\mathrm{CH}_{2} \mathrm{OO}\right](t)=\left[\mathrm{CH}_{2} \mathrm{OO}\right]_{0} e^{-k_{\mathrm{obs}} t}$

The fitting error of $k_{\mathrm{obs}}$ is less than $1 \%$ mostly. Under the conditions of this study, the consumption of $\mathrm{CH}_{2} \mathrm{OO}$ can be described as

$$
\begin{aligned}
-\frac{\mathrm{d}\left[\mathrm{CH}_{2} \mathrm{OO}\right]}{\mathrm{d} t} & =k_{\mathrm{obs}}\left[\mathrm{CH}_{2} \mathrm{OO}\right] \\
& =\left(k_{0}+k_{\mathrm{DMS}+\mathrm{CH}_{2} \mathrm{OO}}[\mathrm{DMS}]\right)\left[\mathrm{CH}_{2} \mathrm{OO}\right],
\end{aligned}
$$

where $k_{0}$ represents the sum of the effective rate coefficients for all consumption channels of $\mathrm{CH}_{2} \mathrm{OO}$ except its reaction with DMS, which is described as the bimolecular rate coefficient $k_{\mathrm{DMS}}+\mathrm{CH}_{2} \mathrm{OO}$.

The $\mathrm{CH}_{2} \mathrm{OO}$ decay rate coefficients $k_{\text {obs }}$ as functions of [DMS] for different photolysis laser fluences are summarized in Fig. 2. At higher laser fluences, more $\mathrm{CH}_{2} \mathrm{OO}$ and radical byproducts are generated, resulting in shorter $\mathrm{CH}_{2} \mathrm{OO}$ lifetimes (see Fig. S7: plot of $k_{0}$ against $\left[\mathrm{CH}_{2} \mathrm{I}_{2}\right] \times I_{308 \mathrm{~nm}}$ ),

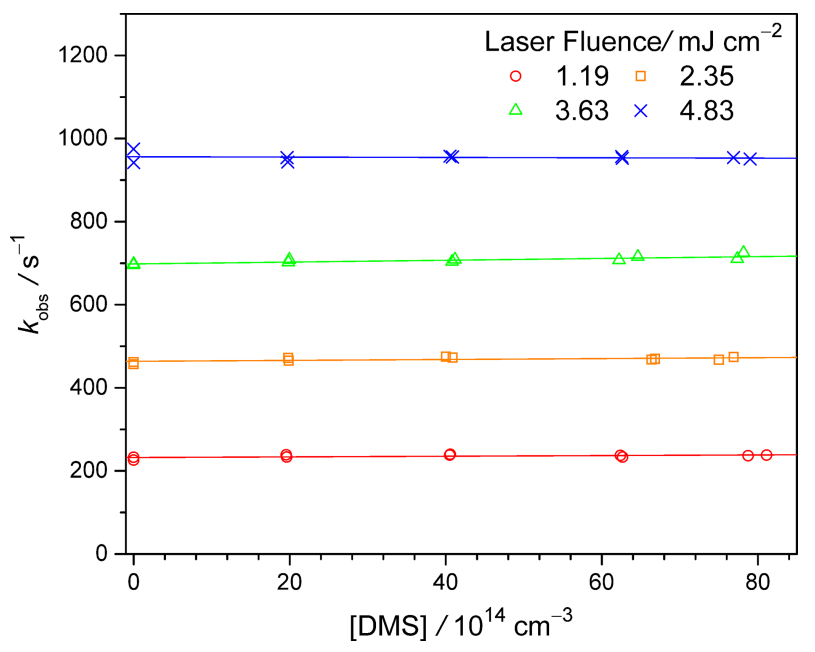

Figure 2. $k_{\mathrm{obs}}$ of $\mathrm{CH}_{2} \mathrm{OO}$ against [DMS] determined from experiments (Exp\#1-4, Table S1) at different photolysis laser fluences $I_{308 \mathrm{~nm}}$; solid lines are linear fits. For each data point, the error of the single exponential fitting is less than $1 \%$ (thus not shown).

similar to previous works (Smith et al., 2016; Li et al., 2020; Zhou et al., 2019). The slopes of the linear fits of Fig. 2 would correspond to $k_{\mathrm{DMS}}+\mathrm{CH}_{2} \mathrm{OO}$ (see Eq. 2). However, the slope values are quite small, close to our detection limit (Lin et al., 2018). Within experimental uncertainty, $k_{\mathrm{DMS}+\mathrm{CH}_{2} \mathrm{OO}}$ exhibits no clear correlation to the photolysis laser fluence and other experimental conditions like $\left[\mathrm{CH}_{2} \mathrm{I}_{2}\right]$ (see Table S1 and Fig. S9). From a total of 11 experimental data sets (Exp\#1-11, Table S1), we inferred an average $k_{\mathrm{DMS}+\mathrm{CH}_{2} \mathrm{OO}}=(1.2 \pm 1.0) \times 10^{-15} \mathrm{~cm}^{3} \mathrm{~s}^{-1}$ (error bar is 1 standard deviation of the 11 data points).

\subsection{Test of the effect of DMS photolysis}

Although the absorption cross section of DMS is quite small $\left(1.28 \times 10^{-20} \mathrm{~cm}^{2}\right.$ at $248 \mathrm{~nm}$ and $<1 \times 10^{-22} \mathrm{~cm}^{2}$ at $308 \mathrm{~nm}$ ) (Limão-Vieira et al., 2002), the photolysis of DMS, especially at $248 \mathrm{~nm}$, should be considered. We have performed a quantitative estimation of radical concentrations originating from the photolysis of DMS under the experimental conditions of this work (Sect. S5 in the Supplement) and show the results in Table S4.

In order to reduce the influence of DMS photolysis for the MVKO experiments, which require $248 \mathrm{~nm}$ photolysis (see Sect. 3.3), we constrain [DMS] $\leq 1.7 \times 10^{15} \mathrm{~cm}^{-3}$ and the laser fluence $I_{248 \mathrm{~nm}} \leq 3.72 \mathrm{~mJ} \mathrm{~cm}^{-2}$. Then the amount of dissociated [DMS] would be $\leq 1 \times 10^{11} \mathrm{~cm}^{-3}$, smaller than the dissociated $\left[\mathrm{CH}_{2} \mathrm{I}_{2}\right] \cong 1.2 \times 10^{12} \mathrm{~cm}^{-3}$ by an order of magnitude or more.

The expected products of DMS photolysis are $\mathrm{CH}_{3}+\mathrm{CH}_{3} \mathrm{~S}$ (Bain et al., 2018). Under the presence of $\mathrm{O}_{2}$ (10 Torr), $\mathrm{CH}_{3}$ would be converted into $\mathrm{CH}_{3} \mathrm{OO}$. These radicals $\left(\mathrm{CH}_{3}, \mathrm{CH}_{3} \mathrm{OO}\right.$, and $\left.\mathrm{CH}_{3} \mathrm{~S}\right)$ are less reactive than 
I atoms or CIs. Thus, the small amount of dissociated [DMS] would only have a minor effect. And indeed, the results of $\mathrm{CH}_{2} \mathrm{OO}+$ DMS reaction obtained with $248 \mathrm{~nm}$ photolysis (Figs. S2, S15, Table S2) are very similar to those with $308 \mathrm{~nm}$ photolysis (Figs. 2, S1, S12-S14, Table S1), indicating the effect of DMS photolysis is very minor. The values of $k_{\mathrm{DMS}+\mathrm{CH}_{2} \mathrm{OO}}$ obtained with $248 \mathrm{~nm}$ photolysis (Table S2) range from $1.6 \times 10^{-15}$ to $3.2 \times 10^{-15} \mathrm{~cm}^{3} \mathrm{~s}^{-1}$, which are only slightly higher than the results obtained with $308 \mathrm{~nm}$ photolysis (see Fig. S9). This indicates that the effect of the DMS photolysis would be on the order of

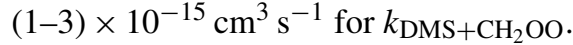

\subsection{MVKO + DMS}

Typical absorbance-time profiles of MVKO under various [DMS] values $\left(\leq 1.3 \times 10^{15} \mathrm{~cm}^{-3}\right)$ are presented in Fig. 3. When generating MVKO via the reaction of $\mathrm{CH}_{3}\left(\mathrm{C}_{2} \mathrm{H}_{3}\right) \mathrm{CI}+\mathrm{O}_{2}$ at a high pressure like 300 Torr, the MVKO signal profiles rise more slowly than those of $\mathrm{CH}_{2} \mathrm{OO}$, with the maximum of the MVKO signal being at about $1.5 \mathrm{~ms}$. Lin et al. (2020) have conducted detailed kinetic and quantum chemical studies on this phenomenon and concluded that the slow rise of the MVKO signal is due to the thermal decomposition of an adduct, $\mathrm{CH}_{3}\left(\mathrm{C}_{2} \mathrm{H}_{3}\right) \mathrm{CIOO}$ $\rightarrow \mathrm{CH}_{3}\left(\mathrm{C}_{2} \mathrm{H}_{3}\right) \mathrm{COO}+$ I. See Supplement (Sect. S3) for details. This difference is consistent with the fact that MVKO is resonance-stabilized due to the extended conjugation of its vinyl group (Barber et al., 2018), and thus the adduct $\mathrm{CH}_{3}\left(\mathrm{C}_{2} \mathrm{H}_{3}\right) \mathrm{CIOO}$ is relatively less stable due to disruption of the conjugation. Nevertheless, no significant changes in the absorbance-time profiles of MVKO with varying [DMS] values can be noted (Fig. 3 inset), indicating the reaction of MVKO + DMS is insignificant. In Fig. 3, we can see that the lifetime of MVKO is on the order of $10 \mathrm{~ms}$ (i.e. a decay rate coefficient of ca. $100 \mathrm{~s}^{-1}$ ) and the variation in the MVKO signal is insignificant upon adding [DMS]. This indicates that the reaction with DMS only changes, at the most, the MVKO lifetime by a small fraction $(<0.1)$ (a larger change would cause obvious deviation from the experimental observations of Fig. 3). Thus, $k_{\mathrm{DMS}+\mathrm{MVKO}}$ can be estimated to be on the order of $\left(100 \mathrm{~s}^{-1}\right)(0.1) /\left(1.3 \times 10^{15} \mathrm{~cm}^{-3}\right) \cong 10^{-14} \mathrm{~cm}^{3} \mathrm{~s}^{-1}$. A similar conclusion can be drawn from additional profiles recorded with different precursor concentrations and photolysis laser fluences and at different pressures (Figs. S16-S18).

To obtain more quantitative values of $k_{\mathrm{DMS}+\mathrm{MVKO}}$, we performed kinetic analysis and the details are given in the Supplement (Sect. S3); selected results of $k_{\mathrm{obs}}$ as functions of [DMS] are presented in Fig. 4. Similar to the $\mathrm{CH}_{2} \mathrm{OO}+\mathrm{DMS}$ case, the rate coefficients for the reaction MVKO + DMS show no clear dependence on laser fluence or precursor concentration. From a total of 15 experiment sets (Exp\#15-29, Table S3), we obtain an average rate coefficient $k_{\mathrm{DMS}+\mathrm{MVKO}}=(6.2 \pm 3.3) \times 10^{-15} \mathrm{~cm}^{3} \mathrm{~s}^{-1}$ (error bar is 1 standard deviation of the 15 data points). As mentioned

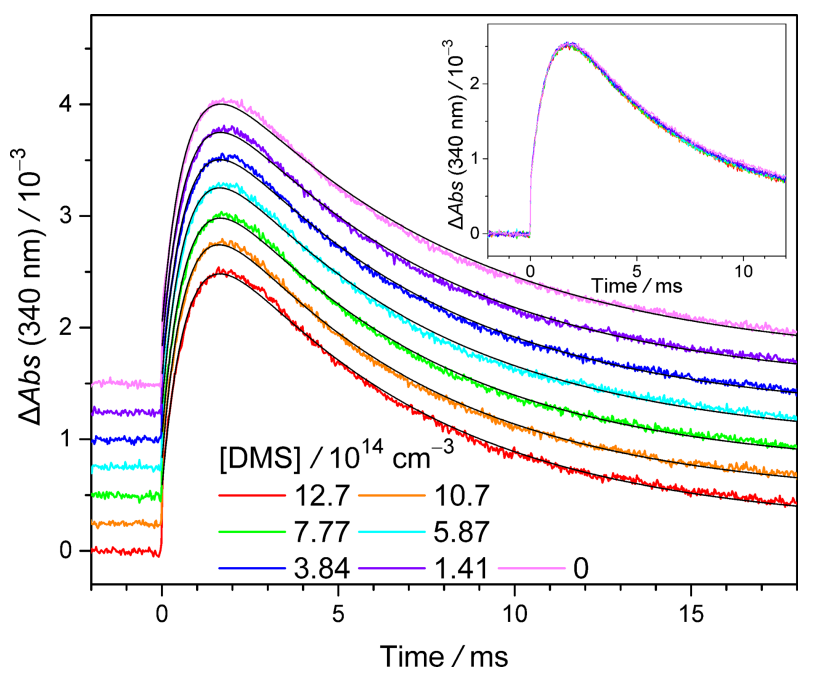

Figure 3. Representative MVKO absorbance-time profiles recorded at $340 \mathrm{~nm}$ under various [DMS] values (298 K, 300 Torr, see Exp\#16 of Table S3). The profiles are upshifted by various amounts to avoid overlapping. The color lines are experimental data and the smooth black lines are the model fit. The inset shows the profiles without upshifting to show the overlapping.

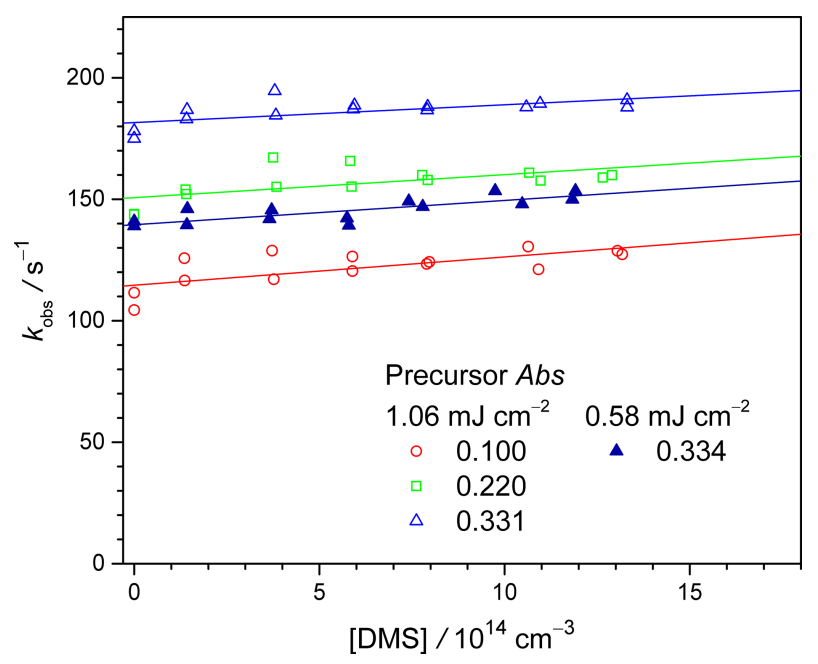

Figure 4. Plot of the observed decay rate coefficient of MVKO $k_{\text {obs }}$ against [DMS] at various laser fluences and precursor absorbances (Exp\#15-18). For each data point, the fitting error bar is less than $1 \%$ (thus, not shown).

above, the MVKO precursor absorbs light weakly at $308 \mathrm{~nm}$ and requires $248 \mathrm{~nm}$ photolysis, such that small amounts of DMS would also be photodissociated. However, the above $\mathrm{CH}_{2} \mathrm{OO}+\mathrm{DMS}$ results indicate that the effect of DMS photolysis in our experiments is minor (on the order of (13) $\times 10^{-15} \mathrm{~cm}^{3} \mathrm{~s}^{-1}$ for $k_{\mathrm{DMS}+\mathrm{CH}_{2} \mathrm{OO}}$ ), but may still lead to overestimation of $k_{\mathrm{DMS}}+\mathrm{MVKO}$. In this regard, the true value of $k_{\text {DMS+MVKO may be smaller than the above number. }}$ 


\subsection{Upper limiting rate coefficients and implications for atmospheric modeling}

The experimental values of $k_{\mathrm{DMS}+\mathrm{CI}}$ (Tables $\mathrm{S} 1$ and S3) are quite small, and their standard deviations are comparable to their average values, indicating that the measured $k_{\text {DMS }+ \text { CI }}$ values are close to our detection limit. Here we choose the boundary of 3 standard deviations as the upper limits for $k_{\mathrm{DMS}+\mathrm{CI}}, k_{\mathrm{DMS}+\mathrm{CH}_{2} \mathrm{OO}} \leq 4.2 \times 10^{-15} \mathrm{~cm}^{3} \mathrm{~s}^{-1}$, and $k_{\text {DMS+MVKO }} \leq 1.6 \times 10^{-14} \mathrm{~cm}^{3} \mathrm{~s}^{-1}$ (Table 1). From Table 1, we can see that for the reactions of both CIs studied, the upper limits of the rate coefficients for their reactions with DMS, $k_{\mathrm{DMS}}$, are much smaller than the literature values of their reactions with $\mathrm{SO}_{2}, k_{\mathrm{SO}_{2}}$. The resulting ratios $k_{\mathrm{DMS}} / k_{\mathrm{SO}_{2}}$ are about 4 orders of magnitude smaller than that reported by Newland et al. (2015).

The steady-state concentrations of CIs, $[\mathrm{CI}]_{\mathrm{ss}}$, in the troposphere have not been well established yet (Kim et al., 2015; Khan et al., 2018; Vereecken et al., 2017; Bonn et al., 2014; Boy et al., 2013). Novelli et al. (2017) have estimated an average $\mathrm{CI}$ concentration of $5 \times 10^{4}$ molecules $\mathrm{cm}^{-3}$ (with an order of magnitude uncertainty) for two environments they have investigated. Due to fast thermal decomposition ( $\mathrm{Li}$ et al., 2020; Smith et al., 2016; Vereecken et al., 2017; Stephenson and Lester, 2020) and/or fast reaction with water vapor (Chao et al., 2015; Lee, 2015; Osborn and Taatjes, 2015; Lin and Chao, 2017; Khan et al., 2018), [CI $]_{s s}$ is expected to be low, at least a couple of orders of magnitude lower than the steady-state concentration of $\mathrm{OH}$ radicals $[\mathrm{OH}]_{\mathrm{ss}}$. The small $k_{\mathrm{DMS}}$ values obtained in this work imply that these reactions would not compete with the conventional DMS oxidation pathways like the reactions with $\mathrm{OH}$ or $\mathrm{NO}_{3}$, of which both the reactant concentrations and rate coefficients are significantly larger. If the DMS reactions with CIs were to be competitive (e.g. $5 \%$ of the overall DMS removal) to those with $\mathrm{NO}_{3}$ (e.g. $\left[\mathrm{NO}_{3}\right] \cong 2.5 \times 10^{8} \mathrm{~cm}^{-3}$ ) and $\mathrm{OH}$ (e.g. $[\mathrm{OH}] \cong 1 \times 10^{6} \mathrm{~cm}^{-3}$ ), the concentration of CIs would have to be unreasonably high, on the order of $10^{11} \mathrm{~cm}^{-3}$.

Newland et al. (2015) performed their experiments on a mixture of three CIs $\left(\mathrm{CH}_{2} \mathrm{OO}\right.$, MVKO, MACRO) as resulting from the ozonolysis of isoprene. The presence of these three CIs, however, cannot explain the difference of 4 orders of magnitude to our results. Due to the lower yield of MACRO compared to the high yield for $\mathrm{CH}_{2} \mathrm{OO}+\mathrm{MVKO}$ (Nguyen et al., 2016; Zhang et al., 2002), it would require an unreasonably large $k_{\mathrm{DMS}+\mathrm{MACRO}}$ to explain the conclusion of Newland et al. (2015). In addition, the electronic structures of MACRO and MVKO are similar. Thus, similar reactivities are expected.

For the determination of the relative rate of the CI + DMS reaction, Newland et al. (2015) monitored the consumption of $\mathrm{SO}_{2}$ over a measurement period of up to $60 \mathrm{~min}$ until approximately $25 \%$ of isoprene was consumed. Additional uncharacterized reaction pathways (e.g. reactions with the products) would lead to a bias in the inferred rate coefficients.
A part of this high complexity of the isoprene-ozone-DMS$\mathrm{SO}_{2}$ system has been discussed by Newland et al. (2015) in the section Experimental uncertainties. Our direct measurements and kinetics are very straightforward; the obtained results for individual CIs may provide useful constraints for related ozonolysis systems.

\subsection{Theoretical predictions for the reaction of $\mathrm{CH}_{2} \mathrm{OO}+\mathrm{DMS}$}

The potential energy surface for $\mathrm{CH}_{2} \mathrm{OO}+$ DMS is shown in Fig. 5. The reaction proceeds through a pre-reaction complex at $-6.0 \mathrm{kcal} \mathrm{mol}^{-1}$ below the free reactants, from which a weakly bonded adduct, $\left(\mathrm{CH}_{3}\right)_{2} \mathrm{SCH}_{2} \mathrm{OO}$ at an energy of $-2.2 \mathrm{kcal} \mathrm{mol}^{-1}$, can be formed through a submerged transition state (TS). At our level of theory, the wave function of this adduct converges to a closed-shell species with very strong zwitterionic character. A potential cycloadduct with a four-membered $-\mathrm{SCH}_{2} \mathrm{OO}$ - ring was found to be unstable. Two accessible product-forming transition states were discovered. The first channel starts from the pre-reaction complex and leads to DMSO $+\mathrm{CH}_{2} \mathrm{O}$ by direct transfer of the terminal $\mathrm{O}$ atom of $\mathrm{CH}_{2} \mathrm{OO}$. A high barrier was found, $6.5 \mathrm{kcal} \mathrm{mol}^{-1}$ above the free reactants, leading to a slow reaction despite the predicted strong exothermicity of $79 \mathrm{kcal} \mathrm{mol}^{-1}$ for this channel. The second channel involves the migration of a DMS methyl $\mathrm{H}$ atom to the outer oxygen of the $\left(\mathrm{CH}_{3}\right)_{2} \mathrm{SCH}_{2} \mathrm{OO}$ adduct with a barrier of $4.7 \mathrm{kcal} \mathrm{mol}^{-1}$ above the free reactants, endothermically forming $\mathrm{CH}_{3} \mathrm{~S}\left(=\mathrm{CH}_{2}\right) \mathrm{CH}_{2} \mathrm{OOH}$ (i.e. the methylidene hydroperoxy equivalent of DMSO) with an energy $3.5 \mathrm{kcal} \mathrm{mol}^{-1}$ above the free reactants. No further low-lying reaction channels for this product were found, including formation of $\mathrm{C} \cdot \mathrm{H}_{2} \mathrm{OOH}+\mathrm{CH}_{3} \mathrm{SC} \cdot \mathrm{H}_{2}$ which has an energy barrier of $\geq 20 \mathrm{kcal} \mathrm{mol}^{-1}$ at the M06-2X/cc-pVDZ level of theory. We did not examine more exotic CI reaction such as insertion in the DMS C-H bonds, as these are known to have comparatively high barriers (Decker et al., 2017). As described in the Supplement, reaction with $\mathrm{O}_{2}$ appears not competitive, as expected given that all intermediates are closed-shell (zwitterionic) species. For the reactions of DMS with substituted $\mathrm{CI}$ (syn- $\mathrm{CH}_{3} \mathrm{CHOO}$ and anti- $\mathrm{CH}_{3} \mathrm{CHOO}$; see Supplement), we found similar complex stability but the adducts are energetically even less favorable, hampering their formation. For MVKO, the adduct was found to be unstable, and formation of DMSO or $\mathrm{H}$ migration of the DMS methyl hydrogen atoms has similar energy barriers as with $\mathrm{CH}_{2} \mathrm{OO}$. The most likely fate of the intermediates in the reaction of CI+DMS is thus reformation of the free reactants, with rapid equilibration between free reactants, pre-reaction complex, and adduct (where applicable). For $\mathrm{CH}_{2} \mathrm{OO}+\mathrm{DMS}$, complex and adduct interconvert at rates $>10^{7} \mathrm{~s}^{-1}$ at room temperature $\left(>4 \times 10^{6} \mathrm{~s}^{-1}\right.$ at $200 \mathrm{~K})$. The lifetime of the complex or adduct with respect to redissociation to the free reactants is estimated to be of the 
Table 1. Summary of the experimental bimolecular reaction rate coefficients of $\mathrm{CI}+\mathrm{SO}_{2}$ and $\mathrm{CI}+\mathrm{DMS}$.

\begin{tabular}{lrrrl}
\hline $\mathrm{CI}$ & $\begin{array}{r}k_{\mathrm{DMS}} / \\
\mathrm{cm}^{3} \mathrm{~s}^{-1}\end{array}$ & $\begin{array}{r}k_{\mathrm{SO}_{2}} / \\
\mathrm{cm}^{3} \mathrm{~s}^{-1}\end{array}$ & $k_{\mathrm{DMS}} / k_{\mathrm{SO}_{2}}$ & Reference \\
\hline $\mathrm{CH}_{2} \mathrm{OO}$ & $<4.2 \times 10^{-15}$ & $3.7 \times 10^{-11^{\mathrm{a}}}$ & $<1.1 \times 10^{-4}$ & This work \\
$\mathrm{MVKO}$ & $<1.6 \times 10^{-14}$ & $4.1 \times 10^{-11^{\mathrm{b}}}$ & $<3.9 \times 10^{-4}$ & This work \\
$\mathrm{CIs}$ & - & - & $3.5 \pm 1.8$ & Newland et al. (2015) \\
\hline & &
\end{tabular}

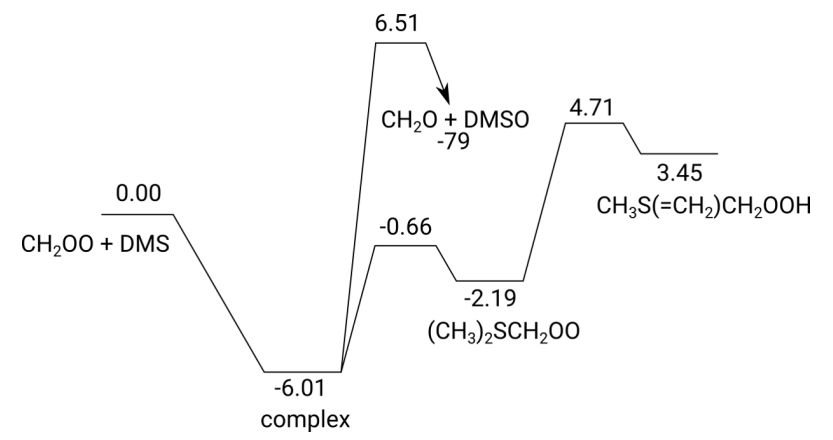

Figure 5. The potential energy surface of $\mathrm{CH}_{2} \mathrm{OO}+\mathrm{DMS}$ $\left(\mathrm{kcal} \mathrm{mol}^{-1}\right.$ ), based on ZPE-corrected (ZPE signifies zero-point energy) $\mathrm{CCSD}(\mathrm{T}) / / \mathrm{M} 06-2 \mathrm{X}$ relative energies.

order of microseconds or less at room temperature, assuming a barrierless complexation channel.

The Supplement also describes a set of calculations at a lower level of theory on the catalytic effect of DMS on a set of unimolecular and bimolecular loss processes of CI reactants. We conclude that DMS does not catalyze unimolecular decay of any of the CIs examined and that DMS does not enhance redissociation of the $\mathrm{CI}+\mathrm{SO}_{2}$ cycloadduct. No information is available on the impact of DMS on the forward reaction rates of $\mathrm{CI}$ bimolecular reactions. In the absence of catalytic effects, the observed elementary reaction of CI with DMS must occur through the pathways depicted in Fig. 5. The total rate coefficient for product formation, i.e. DMSO or $\mathrm{CH}_{3} \mathrm{~S}\left(=\mathrm{CH}_{2}\right) \mathrm{CH}_{2} \mathrm{OOH}$, is predicted at

$k(298 \mathrm{~K})=5.5 \times 10^{-19} \mathrm{~cm}^{3} \mathrm{~s}^{-1} ;$

$k(200-450 \mathrm{~K})=1.34 \times 10^{-44} T^{10.28} \exp (129 \mathrm{~K} / T) \mathrm{cm}^{3} \mathrm{~s}^{-1}$.

Both channels contribute roughly equally at $298 \mathrm{~K}$, with the higher TS being more loose and the lower TS being more rigid. The $\mathrm{CH}_{3} \mathrm{~S}\left(=\mathrm{CH}_{2}\right) \mathrm{CH}_{2} \mathrm{OOH}$ product is intrinsically not very stable and reverses to the $\left(\mathrm{CH}_{3}\right)_{2} \mathrm{SCH}_{2} \mathrm{OO}$ adduct with a rate coefficient $\geq 10^{12} \mathrm{~s}^{-1}$, over a very low reverse barrier of $1.3 \mathrm{kcal} \mathrm{mol}^{-1}$. It seems unlikely that this product can undergo any bimolecular reactions prior to redissociation; reaction with $\mathrm{O}_{2}$ was already found to be very slow. We should then consider that the only stable product effec- tively formed is DMSO $+\mathrm{CH}_{2} \mathrm{O}$, with the following rate coefficient:

$$
\begin{aligned}
k_{\mathrm{eff}}(298 \mathrm{~K})=3.1 & \times 10^{-19} \mathrm{~cm}^{3} \mathrm{~s}^{-1} \\
k_{\mathrm{eff}}(200-450 \mathrm{~K}) & =1.34 \times 10^{-26} T^{4.40} \\
& \exp (-2415 \mathrm{~K} / T) \mathrm{cm}^{3} \mathrm{~s}^{-1} .
\end{aligned}
$$

These theoretical rate predictions are in full agreement with the experimental observations on the elementary reactions of CI with DMS. As documented in the Supplement, similarly slow rate coefficients were predicted for substituted CIs, including MVKO formed in the ozonolysis of isoprene.

\section{Summary}

In this work, we present the first direct kinetic study of the reactions of DMS with $\mathrm{CH}_{2} \mathrm{OO}$ and $\mathrm{MVKO}$, which are the major CIs formed in the ozonolysis of isoprene. We generated the individual CIs by photolysis of the corresponding diiodo precursors in the presence of $\mathrm{O}_{2}$ and monitored their decay via their strong UV absorption at $340 \mathrm{~nm}$ in real time. Our results do not indicate any notable reactivity of DMS with the two CIs studied. We therefore inferred the rate coefficients $k_{\mathrm{DMS}+\mathrm{CH}_{2} \mathrm{OO}} \leq 4.2 \times 10^{-15} \mathrm{~cm}^{3} \mathrm{~s}^{-1}$ and $k_{\text {DMS }+ \text { MVKO }} \leq 1.6 \times 10^{-14} \mathrm{~cm}^{3} \mathrm{~s}^{-1}$. For the reaction of $\mathrm{CH}_{2} \mathrm{OO}+\mathrm{DMS}$, quantum chemistry calculation did not find any low-energy reaction pathways, either by direct reaction or by catalysis of unimolecular reactions, and the calculation predicted an even smaller rate coefficient of $k_{\mathrm{DMS}+\mathrm{CH}_{2} \mathrm{OO}}=3.1 \times 10^{-19} \mathrm{~cm}^{3} \mathrm{~s}^{-1}$ at $298 \mathrm{~K}$. Similarly low rate coefficients are predicted for substituted CIs such as $\mathrm{CH}_{3} \mathrm{CHOO}$ and MVKO. Our results indicate that even in regions with high abundance of CIs and high concentrations of DMS, the isoprene-derived CIs will not notably contribute to the oxidation of DMS.

Data availability. More experimental and calculation data can be found in the Supplement. 
Supplement. The supplement related to this article is available online at: https://doi.org/10.5194/acp-20-12983-2020-supplement.

Author contributions. JJML conceived the experiment. MTK set up the experiment. MTK and IW performed the measurements. MTK analyzed the experimental data. LV performed the theoretical calculations. MTK, IW, CF, LV, and JJML discussed the results and wrote the paper.

Competing interests. The authors declare that they have no conflict of interest.

Acknowledgements. Luc Vereecken is indebted to the Max Planck Graduate Center with the Johannes Gutenberg-Universität Mainz (MPGC), Germany.

Financial support. This research has been supported by the Academia Sinica, the Ministry of Science and Technology, Taiwan (grant nos. MOST 106-2113-M-001-026-MY3 and 108-2911I-001-501(Orchid project)), and the French Ministry of Europe and Foreign Affairs (grant no. PHC Orchid project no. 40930 YC).

Review statement. This paper was edited by James B. Burkholder and reviewed by Mark Blitz and two anonymous referees.

\section{References}

Andreae, M. O., and Crutzen, P. J.: Atmospheric aerosols: biogeochemical sources and role in atmospheric chemistry, Science, 276, 1052-1058, https://doi.org/10.1126/science.276.5315.1052, 1997.

Atkinson, R. and Aschmann, S. M.: Hydroxyl radical production from the gas-phase reactions of ozone with a series of alkenes under atmospheric conditions, Environ. Sci. Technol., 27, 13571363, https://doi.org/10.1021/es00044a010, 1993.

Atkinson, R., Baulch, D. L., Cox, R. A., Crowley, J. N., Hampson, R. F., Hynes, R. G., Jenkin, M. E., Rossi, M. J., and Troe, J.: Evaluated kinetic and photochemical data for atmospheric chemistry: Volume $\mathrm{I}-$ gas phase reactions of $\mathrm{O}_{\mathrm{x}}, \mathrm{HO}_{\mathrm{x}}$, $\mathrm{NO}_{\mathrm{x}}$ and $\mathrm{SO}_{\mathrm{x}}$ species, Atmos. Chem. Phys., 4, 1461-1738, https://doi.org/10.5194/acp-4-1461-2004, 2004.

Atkinson, R., Baulch, D. L., Cox, R. A., Crowley, J. N., Hampson, R. F., Hynes, R. G., Jenkin, M. E., Rossi, M. J., Troe, J., and Wallington, T. J.: Evaluated kinetic and photochemical data for atmospheric chemistry: Volume IV - gas phase reactions of organic halogen species, Atmos. Chem. Phys., 8, 4141-4496, https://doi.org/10.5194/acp-8-4141-2008, 2008.

Bain, M., Hansen, C. S., and Ashfold, M. N. R.: Communication: Multi-mass velocity map imaging study of the ultraviolet photodissociation of dimethyl sulfide using single photon ionization and a PImMS2 sensor, J. Chem. Phys., 149, 081103, https://doi.org/10.1063/1.5048838, 2018.
Barber, V. P., Pandit, S., Green, A. M., Trongsiriwat, N., Walsh, P. J., Klippenstein, S. J., and Lester, M. I.: Four-Carbon Criegee Intermediate from Isoprene Ozonolysis: Methyl Vinyl Ketone Oxide Synthesis, Infrared Spectrum, and OH Production, J. Am. Chem. Soc., 140, 10866-10880, https://doi.org/10.1021/jacs.8b06010, 2018.

Beames, J. M., Liu, F., Lu, L., and Lester, M. I.: UV spectroscopic characterization of an alkyl substituted Criegee intermediate $\mathrm{CH}_{3} \mathrm{CHOO}$, J. Chem. Phys., 138, 244307, https://doi.org/10.1063/1.4810865, 2013.

Bell, R. D. and Wilson, A. K.: $\mathrm{SO}_{3}$ revisited: Impact of tight d augmented correlation consistent basis sets on atomization energy and structure, Chem. Phys. Lett., 394, 105-109, https://doi.org/10.1016/j.cplett.2004.06.127, 2004.

Bonn, B., Bourtsoukidis, E., Sun, T. S., Bingemer, H., Rondo, L., Javed, U., Li, J., Axinte, R., Li, X., Brauers, T., Sonderfeld, H., Koppmann, R., Sogachev, A., Jacobi, S., and Spracklen, D. V.: The link between atmospheric radicals and newly formed particles at a spruce forest site in Germany, Atmos. Chem. Phys., 14, 10823-10843, https://doi.org/10.5194/acp-14-108232014, 2014.

Boy, M., Mogensen, D., Smolander, S., Zhou, L., Nieminen, T., Paasonen, P., Plass-Dülmer, C., Sipilä, M., Petäjä, T., Mauldin, L., Berresheim, H., and Kulmala, M.: Oxidation of $\mathrm{SO}_{2}$ by stabilized Criegee intermediate ( $\mathrm{SCI}$ ) radicals as a crucial source for atmospheric sulfuric acid concentrations, Atmos. Chem. Phys., 13, 3865-3879, https://doi.org/10.5194/acp-13-3865-2013, 2013.

Caravan, R. L., Vansco, M. F., Au, K., Khan, M. A. H., Li, Y.-L., Winiberg, F. A. F., Zuraski, K., Lin, Y.-H., Chao, W., Trongsiriwat, N., Walsh, P. J., Osborn, D. L., Percival, C. J., Lin, J. J.-M., Shallcross, D. E., Sheps, L., Klippenstein, S. J., Taatjes, C. A., and Lester, M. I.: Direct kinetic measurements and theoretical predictions of an isoprene-derived Criegee intermediate, P. Natl. Acad. Sci. USA, 117, 9733-9740, https://doi.org/10.1073/pnas.1916711117, 2020.

Chang, Y.-P., Chang, C.-H., Takahashi, K., and Lin, J. J.-M.: Absolute UV absorption cross sections of dimethyl substituted Criegee intermediate $\left(\mathrm{CH}_{3}\right)_{2} \mathrm{COO}$, Chem. Phys. Lett., 653, 155 160, https://doi.org/10.1016/j.cplett.2016.04.082, 2016.

Chao, W., Hsieh, J.-T., Chang, C.-H., and Lin, J. J.-M.: Direct kinetic measurement of the reaction of the simplest Criegee intermediate with water vapor, Science, 347, 751-754, https://doi.org/10.1126/science.1261549, 2015.

Chao, W., Lin, Y.-H., Yin, C., Lin, W.-H., Takahashi, K., and Lin, J. J.-M.: Temperature and isotope effects in the reaction of $\mathrm{CH}_{3} \mathrm{CHOO}$ with methanol, Phys. Chem. Chem. Phys., 21, 13633-13640, https://doi.org/10.1039/C9CP02534K, 2019.

Charlson, R. J., Lovelock, J. E., Andreae, M. O., and Warren, S. G.: Oceanic phytoplankton, atmospheric sulphur, cloud albedo and climate, Nature, 328, 655-661, https://doi.org/10.1038/326655a0, 1987.

Chhantyal-Pun, R., Davey, A., Shallcross, D. E., Percival, C. J., and Orr-Ewing, A. J.: A kinetic study of the $\mathrm{CH}_{2} \mathrm{OO}$ Criegee intermediate self-reaction, reaction with $\mathrm{SO}_{2}$ and unimolecular reaction using cavity ring-down spectroscopy, Phys. Chem. Chem. Phys., 17, 3617-3626, https://doi.org/10.1039/c4cp04198d, 2015.

Chhantyal-Pun, R., Shannon, R. J., Tew, D. P., Caravan, R. L., Duchi, M., Wong, C., Ingham, A., Feldman, C., McGillen, M. 
R., Khan, M. A. H., Antonov, I. O., Rotavera, B., Ramasesha, K., Osborn, D. L., Taatjes, C. A., Percival, C. J., Shallcross, D. E., and Orr-Ewing, A. J.: Experimental and computational studies of Criegee intermediate reactions with $\mathrm{NH}_{3}$ and $\mathrm{CH}_{3} \mathrm{NH}_{2}$, Phys. Chem. Chem. Phys., 21, 14042-14052, https://doi.org/10.1039/C8CP06810K, 2019.

Cox, R. A., Ammann, M., Crowley, J. N., Herrmann, H., Jenkin, M. E., McNeill, V. F., Mellouki, A., Troe, J., and Wallington, T. J.: Evaluated kinetic and photochemical data for atmospheric chemistry: Volume VII - Criegee intermediates, Atmos. Chem. Phys. Discuss., https://doi.org/10.5194/acp-2020-472, in review, 2020.

Decker, Z. C. J., Au, K., Vereecken, L., and Sheps, L.: Direct experimental probing and theoretical analysis of the reaction between the simplest Criegee intermediate $\mathrm{CH}_{2} \mathrm{OO}$ and isoprene, Phys. Chem. Chem. Phys., 19, 8541-8551, https://doi.org/10.1039/C6CP08602K, 2017.

Dunning, T. H.: Gaussian basis sets for use in correlated molecular calculations. I. The atoms boron through neon and hydrogen, J. Chem. Phys., 90, 1007-1023, 10.1063/1.456153, 1989.

Dunning, T. H., Peterson, K. A., and Wilson, A. K.: Gaussian basis sets for use in correlated molecular calculations. X. The atoms aluminum through argon revisited, J. Chem. Phys., 114, 92449253, 10.1063/1.1367373, 2001.

Eskola, A. J., Wojcik-Pastuszka, D., Ratajczak, E., and Timonen, R. S.: Kinetics of the reactions of $\mathrm{CH}_{2} \mathrm{Br}$ and $\mathrm{CH}_{2} \mathrm{I}$ radicals with molecular oxygen at atmospheric temperatures, Phys. Chem. Chem. Phys., 8, 1416-1424, https://doi.org/10.1039/B516291B, 2006.

Faloona, I.: Sulfur processing in the marine atmospheric boundary layer: A review and critical assessment of modeling uncertainties, Atmos. Environ., 43, 2841-2854, https://doi.org/10.1016/j.atmosenv.2009.02.043, 2009.

Foreman, E. S., Kapnas, K. M., and Murray, C.: Reactions between Criegee intermediates and the inorganic acids $\mathrm{HCl}$ and $\mathrm{HNO}_{3}$ : kinetics and atmospheric implications, Angew. Chem. Int. Edit., 55, 10419-10422, https://doi.org/10.1002/anie.201604662, 2016.

Frisch, M. J., Trucks, G. W., Schlegel, H. B., Scuseria, G. E., Robb, M. A., Cheeseman, J. R., Scalmani, G., Barone, V., Petersson, G. A., Nakatsuji, H., Li, X., Caricato, M., Marenich, A. V., Bloino, J., Janesko, B. G., Gomperts, R., Mennucci, B., Hratchian, H. P., Ortiz, J. V., Izmaylov, A. F., Sonnenberg, J. L., Williams, Ding, F., Lipparini, F., Egidi, F., Goings, J., Peng, B., Petrone, A., Henderson, T., Ranasinghe, D., Zakrzewski, V. G., Gao, J., Rega, N., Zheng, G., Liang, W., Hada, M., Ehara, M., Toyota, K., Fukuda, R., Hasegawa, J., Ishida, M., Nakajima, T., Honda, Y., Kitao, O., Nakai, H., Vreven, T., Throssell, K., Montgomery Jr., J. A., Peralta, J. E., Ogliaro, F., Bearpark, M. J., Heyd, J. J., Brothers, E. N., Kudin, K. N., Staroverov, V. N., Keith, T. A., Kobayashi, R., Normand, J., Raghavachari, K., Rendell, A. P., Burant, J. C., Iyengar, S. S., Tomasi, J., Cossi, M., Millam, J. M., Klene, M., Adamo, C., Cammi, R., Ochterski, J. W., Martin, R. L., Morokuma, K., Farkas, O., Foresman, J. B., and Fox, D. J.: Gaussian 09 software package, Revision B.01, Gaussian 09 Inc., Wallingford, CT, 2009.

Gutbrod, R., Kraka, E., Schindler, R. N., and Cremer, D.: Kinetic and theoretical investigation of the gas-phase ozonolysis of isoprene:? carbonyl oxides as an important source for $\mathrm{OH}$ radi- cals in the atmosphere, J. Am. Chem. Soc., 119, 7330-7342, https://doi.org/10.1021/ja970050c, 1997.

Hatakeyama, S. and Akimoto, H.: Reactions of criegee intermediates in the gas phase, Res. Chem. Intermediat., 20, 503-524, https://doi.org/10.1163/156856794X00432, 1994.

Huang, H.-L., Chao, W., and Lin, J. J.-M.: Kinetics of a Criegee intermediate that would survive high humidity and may oxidize atmospheric $\mathrm{SO}_{2}$, P. Natl. Acad. Sci. USA, 112, 10857-10862, https://doi.org/10.1073/pnas.1513149112 2015.

Jardine, K., Yañez-Serrano, A. M., Williams, J., Kunert, N., Jardine, A., Taylor, T., Abrell, L., Artaxo, P., Guenther, A., Hewitt, C. N., House, E., Florentino, A. P., Manzi, A., Higuchi, N., Kesselmeier, J., Behrendt, T., Veres, P. R., Derstroff, B., Fuentes, J. D., Martin, S. T., and Andreae, M. O.: Dimethyl sulfide in the Amazon rain forest, Global Biogeochem. Cy., 29, 19-32, https://doi.org/10.1002/2014GB004969, 2015.

Johnson, D., Lewin, A. G., and Marston, G.: The Effect of CriegeeIntermediate Scavengers on the $\mathrm{OH}$ Yield from the Reaction of Ozone with 2-methylbut-2-ene, J. Phys. Chem. A, 105, 2933 2935, https://doi.org/10.1021/jp003975e, 2001.

Johnson, D. and Marston, G.: The gas-phase ozonolysis of unsaturated volatile organic compounds in the troposphere, Chem. Soc. Rev., 37, 699-716, https://doi.org/10.1039/B704260B, 2008.

Khan, M. A. H., Percival, C. J., Caravan, R. L., Taatjes, C. A., and Shallcross, D. E.: Criegee intermediates and their impacts on the troposphere, Environmental Science: Processes \& Impacts, 20, 437-453, https://doi.org/10.1039/C7EM00585G, 2018.

Kim, S., Guenther, A., Lefer, B., Flynn, J., Griffin, R., Rutter, A. P., Gong, L., and Cevik, B. K.: Potential role of stabilized Criegee radicals in sulfuric acid production in a high biogenic VOC environment, Environ. Sci. Technol., 49, 3383-3391, https://doi.org/10.1021/es505793t, 2015.

Lee, Y. P.: Perspective: Spectroscopy and kinetics of small gaseous Criegee intermediates, J. Chem. Phys., 143, 020901, https://doi.org/10.1063/1.4923165, 2015.

Lewis, T. R., Blitz, M. A., Heard, D. E., and Seakins, P. W.: Direct evidence for a substantive reaction between the Criegee intermediate, $\mathrm{CH}_{2} \mathrm{OO}$, and the water vapour dimer, Phys. Chem. Chem. Phys., 17, 4859-4863, https://doi.org/10.1039/C4CP04750H, 2015.

Li, Y.-L., Lin, Y.-H., Yin, C., Takahashi, K., Chiang, C.-Y., Chang, Y.-P., and Lin, J. J.-M.: Temperature-dependent rate coefficient for the reaction of $\mathrm{CH}_{3} \mathrm{SH}$ with the simplest Criegee intermediate, J. Phys. Chem. A, 123, 4096-4103, https://doi.org/10.1021/acs.jpca.8b12553, 2019.

Li, Y.-L., Kuo, M.-T., and Lin, J. J.-M.: Unimolecular decomposition rates of a methyl-substituted Criegee intermediate syn- $\mathrm{CH}_{3} \mathrm{CHOO}$, RSC Advances, 10, 8518-8524, https://doi.org/10.1039/D0RA01406K, 2020.

Limão-Vieira, P., Eden, S., Kendall, P. A., Mason, N. J., and Hoffmann, S. V.: High resolution VUV photo-absorption crosssection for dimethylsulphide, (CH3) ${ }_{2} \mathrm{~S}$, Chem. Phys. Lett., 366, 343-349, https://doi.org/10.1016/S0009-2614(02)01651-2, 2002.

Lin, H.-Y., Huang, Y.-H., Wang, X., Bowman, J. M., Nishimura, Y., Witek, H. A., and Lee, Y.-P.: Infrared identification of the Criegee intermediates syn- and anti- $\mathrm{CH}_{3} \mathrm{CHOO}$, and their distinct conformation-dependent reactivity, Nat. Commun., 6, 7012, https://doi.org/10.1038/ncomms8012, 2015. 
Lin, J. J.-M., and Chao, W.: Structure-dependent reactivity of Criegee intermediates studied with spectroscopic methods, Chem. Soc. Rev., 46, 7483-7497, https://doi.org/10.1039/C7CS00336F, 2017.

Lin, Y.-H., Takahashi, K., and Lin, J. J.-M.: Reactivity of Criegee intermediates toward carbon dioxide, J. Phys. Chem. Lett., 9, 184188, https://doi.org/10.1021/acs.jpclett.7b03154, 2018.

Lin, Y.-H., Li, Y.-L., Chao, W., Takahashi, K., and Lin, J. J.-M.: The role of the iodine-atom adduct in the synthesis and kinetics of methyl vinyl ketone oxide - a resonance-stabilized Criegee intermediate, Phys. Chem. Chem. Phys., 22, 1360313612, https://doi.org/10.1039/D0CP02085K, 2020.

Liu, F., Beames, J. M., Green, A. M., and Lester, M. I.: UV spectroscopic characterization of dimethyl- and ethylsubstituted carbonyl oxides, J. Phys. Chem. A, 118, 2298-2306, https://doi.org/10.1021/jp412726z, 2014a.

Liu, F., Beames, J. M., Petit, A. S., McCoy, A. B., and Lester, M. I.: Infrared-driven unimolecular reaction of $\mathrm{CH}_{3} \mathrm{CHOO}$ Criegee intermediates to $\mathrm{OH}$ radical products, Science, 345, 1596-1598, https://doi.org/10.1126/science.1257158, 2014b.

Liu, Y., Bayes, K. D., and Sander, S. P.: Measuring Rate Constants for Reactions of the Simplest Criegee Intermediate $\left(\mathrm{CH}_{2} \mathrm{OO}\right)$ by Monitoring the OH Radical, J. Phys. Chem. A, 118, 741-747, 10.1021/jp407058b, 2014c.

McCarthy, M. C., Cheng, L., Crabtree, K. N., Martinez, O., Nguyen, T. L., Womack, C. C., and Stanton, J. F.: The simplest Criegee intermediate $\left(\mathrm{H}_{2} \mathrm{C}-\mathrm{O}-\mathrm{O}\right)$ : isotopic spectroscopy, equilibrium structure, and possible formation from atmospheric lightning, J. Phys. Chem. Lett., 4, 4133-4139, https://doi.org/10.1021/jz4023128, 2013.

Meidan, D., Holloway, J. S., Edwards, P. M., Dubé, W. P., Middlebrook, A. M., Liao, J., Welti, A., Graus, M., Warneke, C., Ryerson, T. B., Pollack, I. B., Brown, S. S., and Rudich, Y.: Role of Criegee intermediates in secondary sulfate aerosol formation in nocturnal power plant plumes in the southeast US, ACS Earth Space Chem., 3, 748-759, https://doi.org/10.1021/acsearthspacechem.8b00215, 2019.

Mir, Z. S., Lewis, T. R., Onel, L., Blitz, M. A., Seakins, P. W., and Stone, D.: $\mathrm{CH}_{2} \mathrm{OO}$ Criegee intermediate UV absorption crosssections and kinetics of $\mathrm{CH}_{2} \mathrm{OO}+\mathrm{CH}_{2} \mathrm{OO}$ and $\mathrm{CH}_{2} \mathrm{OO}+\mathrm{I}$ as a function of pressure, Phys. Chem. Chem. Phys., 22, 9448-9459, https://doi.org/10.1039/D0CP00988A, 2020.

Nakajima, M., Yue, Q., and Endo, Y.: Fourier-transform microwave spectroscopy of an alkyl substituted Criegee intermediate anti- $\mathrm{CH}_{3} \mathrm{CHOO}$, J. Mol. Spectrosc., 310, 109-112, https://doi.org/10.1016/j.jms.2014.11.004, 2015.

Newland, M. J., Rickard, A. R., Vereecken, L., Muñoz, A., Ródenas, M., and Bloss, W. J.: Atmospheric isoprene ozonolysis: impacts of stabilised Criegee intermediate reactions with $\mathrm{SO}_{2}$, $\mathrm{H}_{2} \mathrm{O}$ and dimethyl sulfide, Atmos. Chem. Phys., 15, 9521-9536, https://doi.org/10.5194/acp-15-9521-2015, 2015.

Nguyen, T. B., Tyndall, G. S., Crounse, J. D., Teng, A. P., Bates, K. H., Schwantes, R. H., Coggon, M. M., Zhang, L., Feiner, P., Milller, D. O., Skog, K. M., Rivera-Rios, J. C., Dorris, M., Olson, K. F., Koss, A., Wild, R. J., Brown, S. S., Goldstein, A. H., de Gouw, J. A., Brune, W. H., Keutsch, F. N., Seinfeld, J. H., and Wennberg, P. O.: Atmospheric fates of Criegee intermediates in the ozonolysis of isoprene, Phys. Chem. Chem. Phys., 18, 10241-10254, https://doi.org/10.1039/C6CP00053C, 2016.
Novelli, A., Vereecken, L., Lelieveld, J., and Harder, H.: Direct observation of $\mathrm{OH}$ formation from stabilised Criegee intermediates, Phys. Chem. Chem. Phys., 16, 19941-19951, 10.1039/C4CP02719A, 2014.

Novelli, A., Hens, K., Tatum Ernest, C., Martinez, M., Nölscher, A. C., Sinha, V., Paasonen, P., Petäjä, T., Sipilä, M., Elste, T., PlassDülmer, C., Phillips, G. J., Kubistin, D., Williams, J., Vereecken, L., Lelieveld, J., and Harder, H.: Estimating the atmospheric concentration of Criegee intermediates and their possible interference in a FAGE-LIF instrument, Atmos. Chem. Phys., 17, 78077826, https://doi.org/10.5194/acp-17-7807-2017, 2017.

Osborn, D. L. and Taatjes, C. A.: The physical chemistry of Criegee intermediates in the gas phase, Int. Rev. Phys. Chem., 34, 309360, 10.1080/0144235x.2015.1055676, 2015.

Percival, C. J., Welz, O., Eskola, A. J., Savee, J. D., Osborn, D. L., Topping, D. O., Lowe, D., Utembe, S. R., Bacak, A., M c Figgans, G., Cooke, M. C., Xiao, P., Archibald, A. T., Jenkin, M. E., Derwent, R. G., Riipinen, I., Mok, D. W. K., Lee, E. P. F., Dyke, J. M., Taatjes, C. A., and Shallcross, D. E.: Regional and global impacts of Criegee intermediates on atmospheric sulphuric acid concentrations and first steps of aerosol formation, Faraday Discuss., 165, 45-73, https://doi.org/10.1039/C3FD00048F, 2013.

Purvis, G. D., and Bartlett, R. J.: A full coupled-cluster singles and doubles model: The inclusion of disconnected triples, J. Chem. Phys., 76, 1910-1918, https://doi.org/10.1063/1.443164, 1982.

Sander, S. P., Abbat, J., Barker, J. R., Burkholder, J. B., Friedl, R. R., Golden, D. M., Huie, R. E., Kolb, C. E., Kurylo, M. J., Moortgat, G. K., Orkin, V. L., and Wine, P. H.: Chemical kinetics and photochemical data for use in atmospheric studies, Evaluation No. 17, in: hJPL Publication 10-6, Pasadena, 2011.

Sheps, L.: Absolute ultraviolet absorption spectrum of a Criegee intermediate $\mathrm{CH}_{2} \mathrm{OO}$, J. Phys. Chem. Lett., 4, 4201-4205, https://doi.org/10.1021/jz402191w, 2013.

Smith, M. C., Ting, W.-L., Chang, C.-H., Takahashi, K., Boering, K. A., and Lin, J. J.-M.: UV absorption spectrum of the C2 Criegee intermediate $\mathrm{CH}_{3} \mathrm{CHOO}$, J. Chem. Phys., 141, 074302, https://doi.org/10.1063/1.4892582, 2014.

Smith, M. C., Chao, W., Takahashi, K., Boering, K. A., and Lin, J. J.-M.: Unimolecular decomposition rate of the Criegee intermediate $\left(\mathrm{CH}_{3}\right)_{2} \mathrm{COO}$ measured directly with $\mathrm{UV}$ absorption spectroscopy, J. Phys. Chem. A, 120, 4789-4798, https://doi.org/10.1021/acs.jpca.5b12124, 2016.

Stephenson, T. A. and Lester, M. I.: Unimolecular decay dynamics of Criegee intermediates: energy-resolved rates, thermal rates, and their atmospheric impact, Int. Rev. Phys. Chem., 39, 1-33, https://doi.org/10.1080/0144235X.2020.1688530, 2020.

Stone, D., Blitz, M., Daubney, L., Howes, N. U. M., and Seakins, P. W.: Kinetics of $\mathrm{CH}_{2} \mathrm{OO}$ reactions with $\mathrm{SO}_{2}, \mathrm{NO}_{2}, \mathrm{NO}, \mathrm{H}_{2} \mathrm{O}$ and $\mathrm{CH}_{3} \mathrm{CHO}$ as a function of pressure, Phys. Chem. Chem. Phys., 16, 1139-1149, https://doi.org/10.1039/C3CP54391A, 2014.

Su, M.-N. and Lin, J. J.-M.: Note: A transient absorption spectrometer using an ultra bright laser-driven light source, Rev. Sci. Instrum., 84, 086106, https://doi.org/10.1063/1.4818977, 2013.

Su, Y.-T., Huang, Y.-H., Witek, H. A., and Lee, Y.P.: Infrared absorption spectrum of the simplest Criegee intermediate $\mathrm{CH}_{2} \mathrm{OO}$, Science, 340, 174-176, https://doi.org/10.1126/science.1234369, 2013.

Taatjes, C. A., Welz, O., Eskola, A. J., Savee, J. D., Osborn, D. L., Lee, E. P. F., Dyke, J. M., Mok, D. W. K., Shallcross, D. 
E., and Percival, C. J.: Direct measurement of Criegee intermediate $\left(\mathrm{CH}_{2} \mathrm{OO}\right)$ reactions with acetone, acetaldehyde, and hexafluoroacetone, Phys. Chem. Chem. Phys., 14, 10391-10400, 10.1039/c2cp40294g, 2012.

Taatjes, C. A., Welz, O., Eskola, A. J., Savee, J. D., Scheer, A. M., Shallcross, D. E., Rotavera, B., Lee, E. P. F., Dyke, J. M., Mok, D. K. W., Osborn, D. L., and Percival, C. J.: Direct measurements of conformer-dependent reactivity of the Criegee intermediate $\mathrm{CH}_{3} \mathrm{CHOO}$, Science, 340, 177-180, https://doi.org/10.1126/science.1234689, 2013.

Ting, W.-L., Chen, Y.-H., Chao, W., Smith, M. C., and Lin, J. J.M.: The UV absorption spectrum of the simplest Criegee intermediate $\mathrm{CH}_{2} \mathrm{OO}$, Phys. Chem. Chem. Phys., 16, 10438-10443, https://doi.org/10.1039/C4CP00877D, 2014.

Truhlar, D. G., Garrett, B. C., and Klippenstein, S. J.: Current Status of Transition-State Theory, J. Phys. Chem., 100, 12771-12800, https://doi.org/10.1021/jp953748q, 1996.

Vansco, M. F., Marchetti, B., and Lester, M. I.: Electronic spectroscopy of methyl vinyl ketone oxide: a four-carbon unsaturated Criegee intermediate from isoprene ozonolysis, J. Chem. Phys., 149, 244309, https://doi.org/10.1063/1.5064716, 2018.

Vansco, M. F., Marchetti, B., Trongsiriwat, N., Bhagde, T., Wang, G., Walsh, P. J., Klippenstein, S. J., and Lester, M. I.: Synthesis, electronic spectroscopy, and photochemistry of methacrolein oxide: a four-carbon unsaturated Criegee intermediate from isoprene ozonolysis, J. Am. Chem. Soc., 141, 15058-15069, https://doi.org/10.1021/jacs.9b05193, 2019.

Vereecken, L., Novelli, A., and Taraborrelli, D.: Unimolecular decay strongly limits the atmospheric impact of Criegee intermediates, Phys. Chem. Chem. Phys., 19, 31599-31612, 2017.

Wang, M. Y., Yao, L., Zheng, J., Wang, X., Chen, J. M., Yang, X., Worsnop, D. R., Donahue, N. M., and Wang, L.: Reactions of atmospheric particulate stabilized Criegee intermediates lead to high-molecular-weight aerosol components, Environ. Sci. Technol., 50, 5702-5710, https://doi.org/10.1021/acs.est.6b02114, 2016.
Welz, O., Savee, J. D., Osborn, D. L., Vasu, S. S., J., P. C., Shallcross, D. E., and Taatjes, C. A.: Direct kinetic measurements of Criegee intermediate $\mathrm{CH}_{2} \mathrm{OO}$ formed by reaction of $\mathrm{CH}_{2} \mathrm{I}$ with $\mathrm{O}_{2}$, Science, 335, 204-204, https://doi.org/10.1126/science.1213229, 2012.

Welz, O., Eskola, A. J., Sheps, L., Rotavera, B., Savee, J. D., Scheer, A. M., Osborn, D. L., Lowe, D., Murray B., A., Xiao, P., Khan, M. A. H., Percival, C. J., Shallcross, D. E., and Taatjes, C. A.: Rate coefficients of $\mathrm{C} 1$ and $\mathrm{C} 2$ Criegee intermediate reactions with formic and acetic acid near the collision limit: direct kinetics measurements and atmospheric implications, Angew. Chem., Int Edit., 53, 4547-4550, https://doi.org/10.1002/anie.201400964, 2014.

Yvon, S. A., Saltzman, E. S., Cooper, D. J., Bates, T. S., and Thompson, A. M.: Atmospheric sulfur cycling in the tropical Pacific marine boundary layer $\left(12^{\circ} \mathrm{S}, 135^{\circ} \mathrm{W}\right)$ : a comparison of field data and model results: 1. dimethylsulfide, J. Geophys. Res.-Atmos., 101, 6899-6909, https://doi.org/10.1029/95JD03356, 1996.

Zhang, D., Lei, W., and Zhang, R.: Machanism of OH formation from ozonolysis of isoprene: kinetics and product yield, Chem. Phys. Lett., 358, 171-179, https://doi.org/10.1016/S00092614(02)00260-9, 2002.

Zhao, Y. and Truhlar, D. G.: The M06 suite of density functionals for main group thermochemistry, thermochemical kinetics, noncovalent interactions, excited states, and transition elements: two new functionals and systematic testing of four M06-class functionals and 12 other functionals, Theor. Chem. Acc., 120, 215241, 10.1007/s00214-007-0310-x, 2008.

Zhou, X., Liu, Y., Dong, W., and Yang, X.: Unimolecular reaction rate measurement of syn- $\mathrm{CH}_{3} \mathrm{CHOO}$, J. Phys. Chem. Lett., 10, 4817-4821, https://doi.org/10.1021/acs.jpclett.9b01740, 2019. 